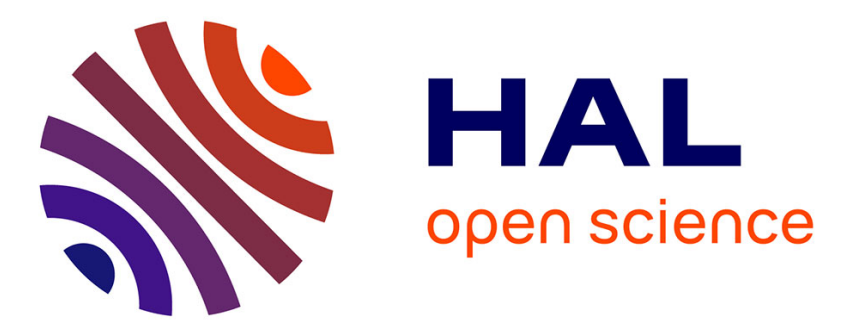

\title{
Energy saving and safe driving assistance system for light vehicles: Experimentation and analysis
}

\author{
Lydie Nouveliere, Saïd Mammar, H.T. Luu
}

\section{To cite this version:}

Lydie Nouveliere, Saïd Mammar, H.T. Luu. Energy saving and safe driving assistance system for light vehicles: Experimentation and analysis. 9th IEEE International Conference on Networking, Sensing and Control (ICNSC 2012), Apr 2012, Pékin, China. pp.346-351, 10.1109/ICNSC.2012.6204942 . hal-00745426

\section{HAL Id: hal-00745426 \\ https://hal.science/hal-00745426}

Submitted on 5 Jul 2021

HAL is a multi-disciplinary open access archive for the deposit and dissemination of scientific research documents, whether they are published or not. The documents may come from teaching and research institutions in France or abroad, or from public or private research centers.
L'archive ouverte pluridisciplinaire HAL, est destinée au dépôt et à la diffusion de documents scientifiques de niveau recherche, publiés ou non, émanant des établissements d'enseignement et de recherche français ou étrangers, des laboratoires publics ou privés. 


\section{Energy Saving and Safe Driving Assistance System for Light Vehicles : Experimentation and Analysis}

\author{
NOUVELIERE L., MAMMAR S. \\ IBISC / LIVIC \\ University of Evry / IFSTTAR IM \\ Evry, France \\ lydie.nouveliere@ibisc.univ-evry.fr
}

\author{
LUU H.-T. \\ LIVIC \\ IFSTTAR IM \\ Versailles, France \\ luutuht@yahoo.com
}

\begin{abstract}
This paper presents an EDAS (Eco-Driving Assistance System) to render a light vehicle low fuel consuming while being safe. A fuel consumption modeling, associated to a speed/gear optimization module, is proposed and used to compute the optimal speed profile and gear ratio to inform the driver in order him to eco-drive. An HMI module is presented and the driver behavior is analyzed face to the indications given by this HMI: are the optimal trajectories easy to be followed? Are the HMI outputs understandable and accepted by the driver? Does this HMI information improve the way of driving in terms of safety, low consumption and comfort? Several experimental results obtained with a prototype vehicle and several drivers are presented in order to evaluate the quality of this EDAS. The analysis deals with the gain obtained for the safety (speed overlaps, headway spacing, speed while approaching a road curve), consumption and covering distance aspects, by comparing a driving without any HMI and a driving with the use of the HMI with a given driver (several drivers have tested this EDAS for the analysis). The experimental results show that this kind of EDAS can save until around $10 \%$ of gasoline and more than $50 \%$ speed overlaps (compared to the legal speed).
\end{abstract}

Energy saving; Eco-Driving Assistance System (EDAS); Experimental application;

\section{INTRODUCTION}

The sector of the road transports does not escape the trend consisting of not emitting too many main Green House Gas (GHG). It is the second largest $\mathrm{CO}_{2}$ emitter with $6.6 \mathrm{Gt}$ in $2008[1,2]$. Nowadays, electric and hybrid vehicles make their appearance, but several technical and technological limits induce still a long time before they will replace our conventional thermal / diesel vehicles. But these electric/hybrid vehicles represent a good alternative to reduce the dependence of our displacements to the fossil energies.

Thanks to the Automated Driving Assistance Systems (ADAS), a today light vehicle is now equipped with several embedded automated systems. These ADAS thus permit to the driver to be safe while improving his comfort. When the automobiles and parts sector appears as one of the main Green House Gas (GHG) transmitter, many efforts must be made to answer to the anti-polluting norms that are more and more restrictive.
One of the fast and low cost solutions consists of reducing the fuel consumption while acting on the changing of the driver behavior. The main objective is then to help the driver to globally adopt a more economical driving, what is more, a more ecological and safer driving. The system advises the driver in any way (speed display, alarms,... [3]) via an HMI. But no active driving assistance system has been developed and commercialized yet. According to Evans (1979), a driver could reduce his fuel consumption by as much as $14 \%$ without increasing trip time, just by reducing acceleration levels and generally driving more "gently", combined with a skillful avoidance of stops. The experiment conducted by LIVIC lab. in the Versailles area, France, confirms a gain between 10 to $20 \%$ can be obtained by changing the driving style. This shows a great potential fuel saving of future actions that will make the driver be awake of economical and ecological driving.

Some prototypes of fuel-efficiency tool support are presented through van der Voort et al. [4]; Hellstrom et al. [5]. These works are carried out in the context of the heavy vehicle. In the field of public transport, the PREDIT-ANR-ANGO project [6] aims at designing a fuel-efficiency driving assistance system for a city bus. Optimal trajectories were computed with a known itinerary and on an exclusive right of way. There are some ADAS on the market like those issued from the GERICO project or from the eco-driving dashboard from HONDA. On the other side, several systems are based on the MDD concept (Modern Drive Devices). The main difference between them comes from the way to give the advice to the driver. The ADAS are able to send the information in realtime, adapted to the journey; the MDD methodology underlines the analysis and devices given to the driver once the journey is finished with some statistical tools in order the driver to improve his next journey.

In this paper, our approach is different from the already existing studies and technical solutions by its strategy used. This one takes into account both infrastructure characteristics and the current vehicle situation. To do that, a digital map containing the road geometry (slopes, curves,...) is used and the legal speed is known [7]. The headway spacing is measured and the vehicle longitudinal characteristics are also known [8,

This work is supported by the ANR (French National Research Agency) VTT program, and developed in the ANR VTT ABV (Low Speed Automation) research project (2009-2013) 
9]. Starting from these data, the problem of optimization of the fuel consumption is formulated and solved with a dynamic programming technique [10]. A real-time strategy is then adopted in order to render the system adaptive to the traffic conditions. A coupling between the safety problem and the low fuel consumption objective is thus reached. After some simulations on MATLAB/SIMULINK, this EDAS (Ecological Driving Assistance System) was tested on a prototype vehicle driving on a national road test track type. An HMI is used to transmit the device to the driver (optimal speed and optimal gear).The experimental results are shown. A first analysis of the economical gain is given.

\section{NOMENCLATURE}

The nomenclature in Table 1 is used all along the paper and defines the vehicle parameters.

TABLE I. VEHICLE PARAMETERS

\begin{tabular}{|c|c|}
\hline $\begin{array}{c}\text { Parameter } \\
\text { Notation }\end{array}$ & Parameter description \\
\hline$x$ & Longitudinal position (m) \\
\hline $\mathrm{v}_{\mathrm{x}}$ & Longitudinal speed $\left(\mathrm{ms}^{-1}\right)$ \\
\hline $\mathrm{r}$ & Wheel radius (m) \\
\hline $\mathrm{M}$ & Vehicle mass (kg) \\
\hline $\mathrm{I}_{\mathrm{e}}, \mathrm{I}_{\mathrm{t}}, \mathrm{I}_{\mathrm{d}}, \mathrm{I}_{\mathrm{w}}$ & $\begin{array}{l}\text { Respective rotational inertias of the engine, } \\
\text { transmission, drive shaft, wheel/axle shaft } \\
\left(\mathrm{kgm}^{2}\right)\end{array}$ \\
\hline $\mathrm{N}_{\mathrm{f}}, \mathrm{N}_{\mathrm{t}}$ & $\begin{array}{l}\text { Transmission numerical ratio and final drive } \\
\text { ratio }\end{array}$ \\
\hline $\mathrm{T}_{\mathrm{e}}$ & Engine torque $(\mathrm{Nm})$ \\
\hline$\omega_{\mathrm{e}}$ & Engine speed $\left(\mathrm{rad} . \mathrm{s}^{-1}\right)$ \\
\hline $\mathrm{g}$ & Gravity $\left(\mathrm{ms}^{-2}\right)$ \\
\hline $\mathrm{C}_{\mathrm{R}}$ & Rolling resistance \\
\hline$\rho$ & Mass density of air $\left(\mathrm{kgm}^{-3}\right)$ \\
\hline $\mathrm{S}$ & Projected frontal area of the vehicle $\left(\mathrm{m}^{2}\right)$ \\
\hline $\mathrm{C}_{\mathrm{x}}$ & Aerodynamic drag coefficient \\
\hline$\theta$ & Road slope (rad) \\
\hline
\end{tabular}

\section{VEHICLE AND CONSUMPTION MODELLING}

\section{A. Vehicle Modelling}

A non slip longitudinal vehicle model is used to simulate the optimization module in order the vehicle to low fuel consume

$$
\begin{aligned}
\dot{x}= & v_{x} \\
\dot{v}_{x}= & \frac{r}{M r^{2}+I_{e t} N_{f}^{2} N_{t}^{2}+I_{d w}}\left(\eta N_{f} N_{t} T_{e}\right. \\
& -r\left(M g C_{R}+\frac{1}{2} \rho S C_{x} v_{x}^{2}+M g \sin (\theta)\right)
\end{aligned}
$$

where $I_{d w}=I_{d} N_{f}^{2}+I_{w}$ and $I_{e t}=I_{e}+I_{t}$.

\section{B. Fuel Consumption Modelling}

A consumption model developed in [11] is used

$$
\begin{gathered}
\text { if } T_{e}>0 \\
f c=\beta_{1}+\beta_{2} w_{e}+\beta_{3} w_{e} T_{e}+\beta_{4} T_{e}+\beta_{5} T_{e}^{2} \\
\text { if } T_{e} \leq 0 \\
f c=\alpha+\gamma w_{e}+\theta w_{e}^{2}
\end{gathered}
$$

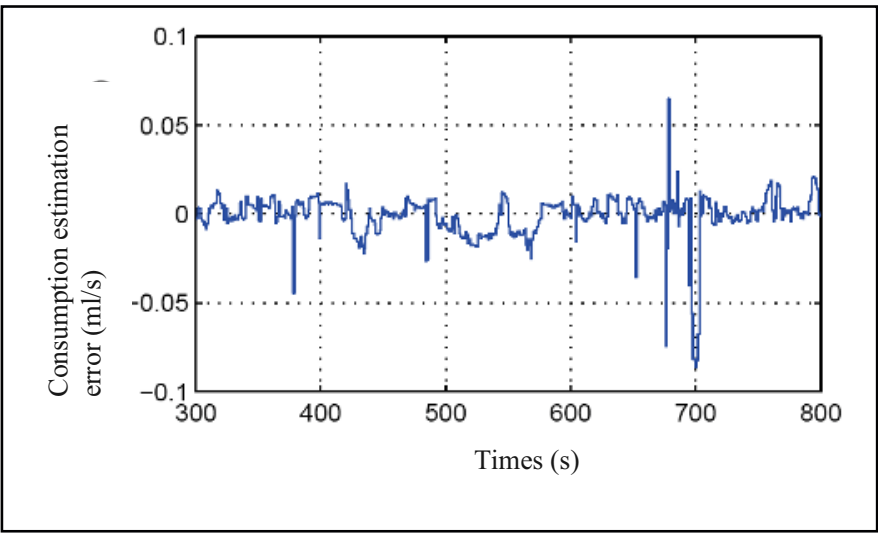

Figure 1. Estimation error of the fuel consumption.

The figure 1 shows that the estimation of the parameters of the consumption model (2) from experimental values of the fuel consumption for a light vehicle is not very high: less than $2.5 \%$ for the major part of the data, until less than $9 \%$ for the higher error.

\section{OPTIMIZATION MODULE}

The proposed ADAS is based on a Dynamic Programming (DP) method used to calculate the optimal speed profile and the optimal gear ratio to be sent to the driver in real-time.

\section{A. Fuel Consumption Optimization: Methodology}

The fuel optimal control problem is formulated under its classical discrete form where $X_{k}=\left[\begin{array}{c}x_{k} \\ v_{x_{k}}\end{array}\right]$ is the state vector 
and $U_{k}=\left[\begin{array}{c}T_{e_{k}} \\ G_{k}\end{array}\right]$ is the control input which gathers the engine torque and the gear ratio. The DP method is then written

$$
\begin{aligned}
& J_{N}=\varsigma_{N}\left(X_{N}\right) \text { for } k=N-1 \ldots 0 \\
& J_{k}\left(X_{N}\right)=\min _{U_{k}}\left(\varsigma_{k}\left(X_{k}, U_{k}\right)+J_{k+1}\left(f\left(X_{k}, U_{k}\right)\right)\right)
\end{aligned}
$$

with the criterium $J$ expressed as follows

$$
J=Q_{1} \cdot F C+Q_{2} \cdot T+Q_{3} \cdot S M O O T H
$$

where $F C=\sum_{k=0}^{k-1} f c_{k}\left(w_{e_{k}}, T_{e_{k}}\right)$ and $T$ is the trip time.

SMOOTH is the penalty induced by a speed change. It is tuned

$$
\text { SMOOTH }=\sum_{k=0}^{k-1}\left(\begin{array}{l}
A \cdot\left(\max \left(0, v_{x_{k+1}}-v_{x_{k}}\right)\right)+ \\
(1-A) \cdot \mid\left(\min \left(0, v_{x_{k+1}}-v_{x_{k}}\right)\right.
\end{array}\right)
$$

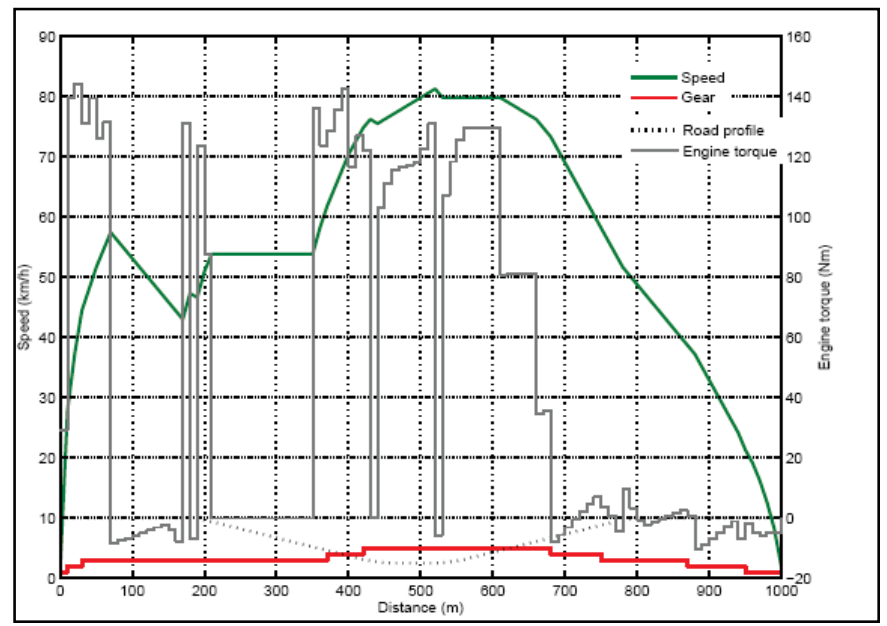

Figure 2. Optimal speed profiles and gear ratio versus weighed coeff. $Q_{i}$.

The detailed methodology and an analysis of these results are given in [10].

\section{B. Safety Criterion}

Two safety values are taken into account: legal speed and safe headway spacing. The legal speed along the trip is known and stored in the road mapping. It is considered as statics safety information. The safe spacing is a dynamics information depending on the speeds of following and preceding vehicles.

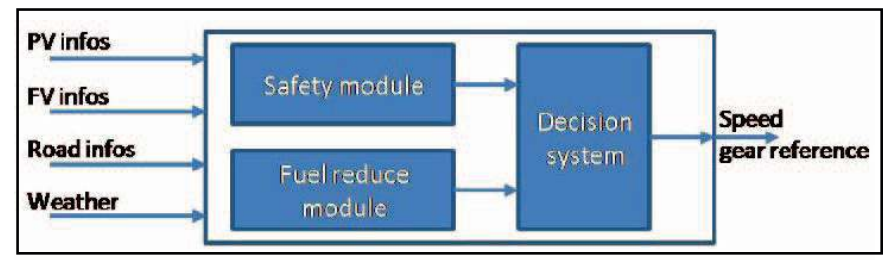

Figure 3. Safety / Optimization modules structure (PV/FV: Preceding/Follower Vehicles).
The $2 s$ safe headway time (French law, 2001) must be respected by the EDAS. A safety margin is calculated and integrated in the optimization module as shown on the figure 3. A fuzzy approach is developed in [9] to obtain the safety margin and the consequence on the optimization module.

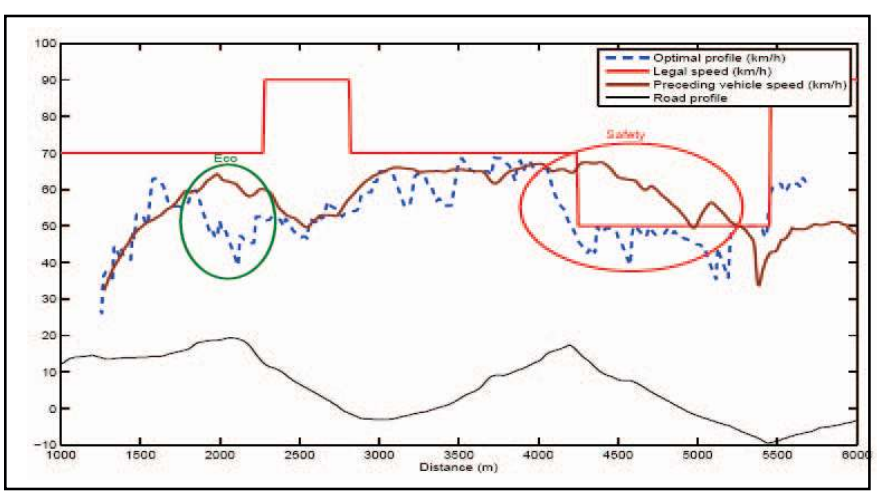

Figure 4. Optimal profiles with $\mathrm{Q} 1=\mathrm{Q} 2=\mathrm{Q} 3=1$.

The figure 4 gives an example of the results obtained with such an EDAS where one can easily see an economical situation (green circle) and a safe situation (red circle).

In the following, this EDAS is implemented on a prototype light vehicle. An HMI was studied and is presented with an analysis about the driver perception.

\section{HuMAN-MACHINE INTERFACE MODULE}

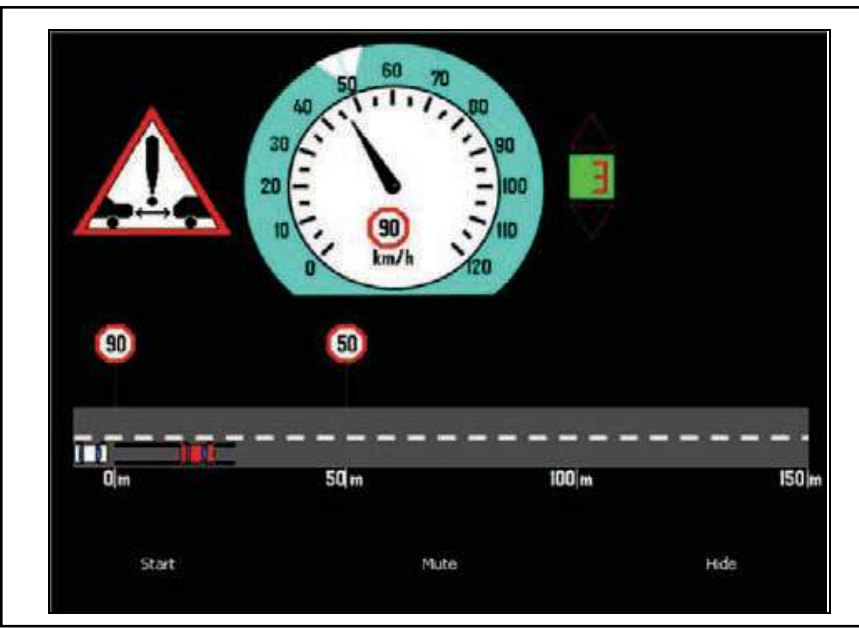

Figure 5. HMI for the proposed EDAS.

The HMI module was conceived with the use of the Qt library in $\mathrm{C}++$. As it is presented on the figure 5 , the current vehicle speed is displayed by the black needle. The white triangle on the circular contour shows the optimal speed from the optimization module. The contour of the speedometer is coupled to a colored code

- If the difference between the optimal speed computed by the optimization module and the current speed 
stays in the definite slot (a margin on either side of the optimal speed), the contour is green.

- If the optimal speed is superior to the current speed, the contour is blue.

- If the optimal speed is inferior to the current speed, the contour is red.

This HMI part permits to know the current driver behavior. In order to add a quantitative perception of the difference between both speeds, a colored shaded off is used.

A small window on the right of the speedometer indicates the current gear ratio. The same colored code is used for it on the up/down arrows ("up" to engage the next up gear ratio, "down" to downshift). With these displays, an immediate information feedback can be given to the driver and the EDAS can propose to him the speed and the gear ratio to be reached.

Besides, the information related to the safety aspect seems to be interesting to show to the driver that the sent data are reliable. That is the reason why a road sign was added and is reflected in an indication relative to the legal speed on the speedometer.

A $150 \mathrm{~m}$ journey is then built on the bottom of the screen, with the follower vehicle displayed at the beginning of this journey. The preceding vehicle is at the headway spacing from the follower vehicle. The length of both parallel black lines on the displayed road represent the safe headway spacing $(2 \mathrm{~s}$ headway time). With this information, the driver knows the safety context in which he is evolving. When the vehicle becomes too closely from the preceding vehicle, a new road sign is displayed to give an alert to the driver (a sound bip can accompany this road sign).

When a particular event occurs not manageable by the HMI module, this one is at the moment desactivated, but when the event disappears, the driver automatically receives the new information from the HMI.

\section{VEHICLE IMPLEMENTATION}

\section{A. Vehicle Equipment}

For our tests, two vehicles are used: a follower vehicle which is a RENAULT Clio Eco2 and a preceding vehicle equipped with a wifi system, a GPS receiver and an on board computer.

In each vehicle, an on-board computer executes the different processing. The preceding vehicle receives the GPS data, its longitudinal speed, its longitudinal acceleration and its covered distance thanks to the odometer of the follower vehicle. The follower vehicle uses its one to manage all the processing of data acquisition, searching the vehicle positions on the digital map, computing the optimal trajectories, transmitting the outputs to the driver via the HMI module. The data transfer from one vehicle to the other is achieved by a wifi connecting channel. Each vehicle has a GPS receiver. A map matching algorithm in the follower vehicle permits it to determine the position of both vehicles on the digital map. This one acquires some data from the CAN bus: speed, acceleration, covered distance, engine speed. The engaged gear ratio is rebuilt from the speed and the engine speed. A laser based radar measures the headway spacing that permits to obtain the relative speed.

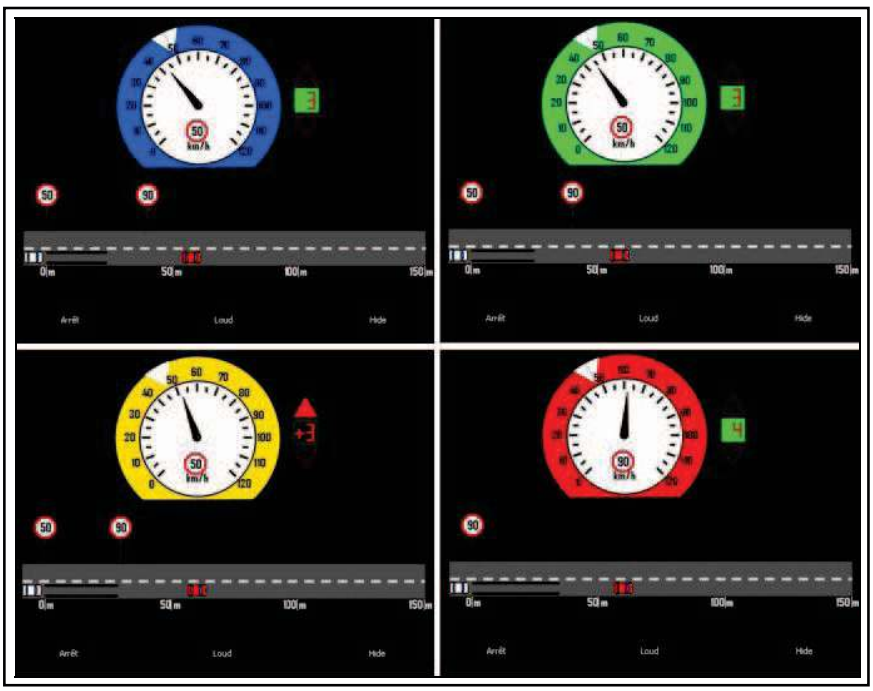

Figure 6. Different HMI scenarios.

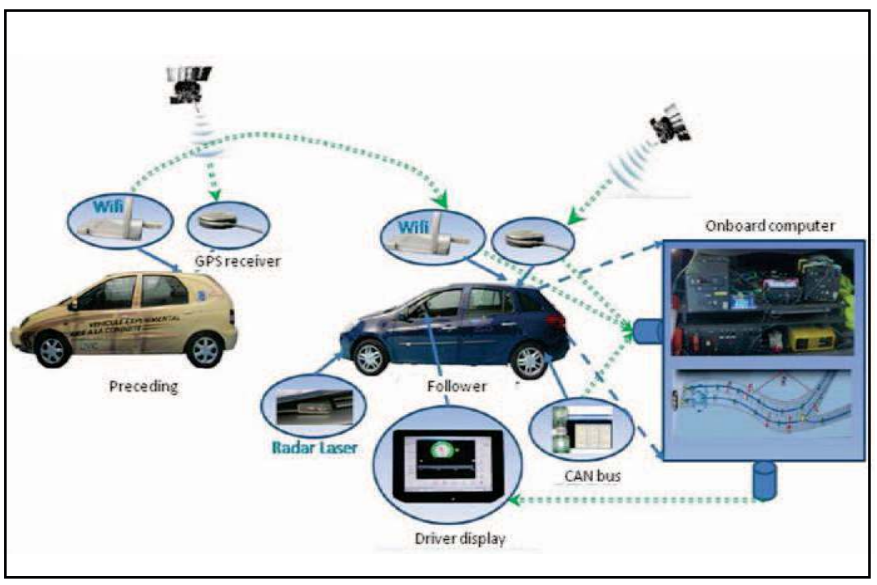

Figure 7. Vehicles equipment.

\section{B. Test Scenarios}

The tests are achieved with 8 voluntary drivers distributed onto 2 phases:

P1: two drivers drive under a free circulating (no traffic constraint), in order to validate the fuel economy effect. Only the legal speed is considered as a safety constraint.

P2: six drivers drive the same vehicle on the same itinerary but with a preceding vehicle (safe headway spacing), to take into account the traffic conditions.

Each driver must realize two different itineraries with two passing on each. The first two passing are covered without the 
EDAS, and it is demanded to the driver to make some effort about his eco-driving style. During their two last passing, the HMI display is offered to the driver. The objective is to see if the EDAS will bring a fuel gain compared to the eco-driving rules.

P1 Phase. Regarding the driver B on the Table 2, he obtains a $1.8 \%$ economical gain. The driver $\mathrm{M}$ achieved a $9.7 \%$ economical gain. One can note that the driver $\mathrm{B}$ did not have a very high gain, compared to the driver $\mathrm{M}$. How to convince the driver B to use this EDAS?

TABLE II. TeSts Without ANy TRAFFic CONSTRAint.

\begin{tabular}{|c|c|c|c|c|}
\hline \multirow{2}{*}{ Driver } & \multicolumn{4}{|c|}{ Legal Speed Overshoots (\%) } \\
\cline { 2 - 5 } & $\begin{array}{c}\text { Trip } \\
\text { Time (s) }\end{array}$ & $\begin{array}{c}\text { Covered } \\
\text { Distance } \\
(\boldsymbol{m})\end{array}$ & $\begin{array}{c}\text { Cumulated } \\
\text { Consumption } \\
(\boldsymbol{l})\end{array}$ & $\begin{array}{c}\text { Middle } \\
\text { Consumption } \\
(\mathbf{I} \mathbf{1 0 0 k m )}\end{array}$ \\
\hline $\begin{array}{c}\text { B without } \\
\text { HMI }\end{array}$ & 651 & 10624 & 0.6263 & 5.8944 \\
\hline $\begin{array}{c}\text { B with } \\
\text { HMI }\end{array}$ & $\begin{array}{c}710 \\
(+8.31 \%)\end{array}$ & 10633 & $\begin{array}{c}0.6151 \\
(-1.79 \%)\end{array}$ & $\begin{array}{c}5.7851 \\
(-1.85 \%)\end{array}$ \\
\hline $\begin{array}{c}\text { M } \\
\text { without } \\
\text { HMI }\end{array}$ & 630 & 10667 & 0.7160 & 6.724 \\
\hline $\begin{array}{c}\text { M with } \\
\text { HMI }\end{array}$ & $\begin{array}{c}691 \\
(+8.83 \%)\end{array}$ & 10674 & $\begin{array}{c}0.6465 \\
(-9.71 \%))\end{array}$ & $\begin{array}{c}6.0566 \\
(-9.93 \%)\end{array}$ \\
\hline
\end{tabular}

On this same Table, the trip time increased of around $8 \%$ with the HMI, thus the question is: is it acceptable by the driver? In a accident gravity point of view, it can be viewed as a way to reduce the average speed thus to decrease the number of accidents.

The Table 3 shows that the use of the HMI brings a very very high gain in respecting the legal speed even with the driver $\mathrm{B}$, it is another one of the advantages of this EDAS.

TABLE III. LEGAL SPEED OVERSHOOTS

\begin{tabular}{|c|c|c|c|}
\hline \multirow{2}{*}{ Driver } & \multicolumn{3}{|c|}{ Legal Speed Overshoots (\%) } \\
\cline { 2 - 4 } & Without HMI & With HMI & Gain (\%) \\
\hline B & 18.3 & 3.38 & -79.23 \\
\hline M & 21.3 & 7.11 & -66.62 \\
\hline
\end{tabular}

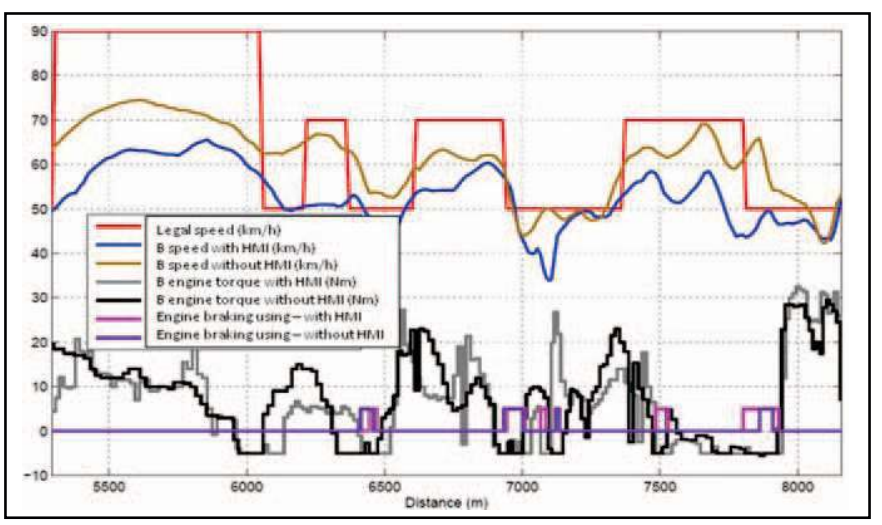

Figure 8. Speed and engine torque profiles of driver B: use of engine braking.
The figure 8 presents the speed and engine torque profiles of the driver B on a $2.5 \mathrm{~km}$ journey, with two passing (with and without HMI). A negative value of the torque corresponds to the use of the engine braking. The pink plot is the engine brake use: when " 0 ", there is no brake. When there is the first legal speed changing, the driver begins to use the engine braking at the same moment on both trips. If we compare both trips with and without the HMI, one can see that without the HMI, the speed profile is always up to the one with the HMI. The reason is the following: as the EDAS has an electronic horizon, it can anticipate on the different events to be coming, contrarily to the driver without the HMI. By this way, the HMI advice being anticipative, the driver can also anticipate his action by following the HMI output, at some moments where the eco-driving rules can be difficult to be applied without an indication like with an electronic horizon.

Furthermore, for the driver B, the engine braking is used at $29.96 \%$ of the total time during his two first passing face to 26.25 on his two last passing. This means that the engine braking can create an influence on the fuel consumption but it is not a dominant variable.

P2 Phase. Now, the traffic conditions are taken into account. Considering the Table 4, all the drivers induce a fuel economy just by following the instructions of the HMI. This gain varies from $1.6 \%$ to $12.9 \%$, in function of the considered driver.

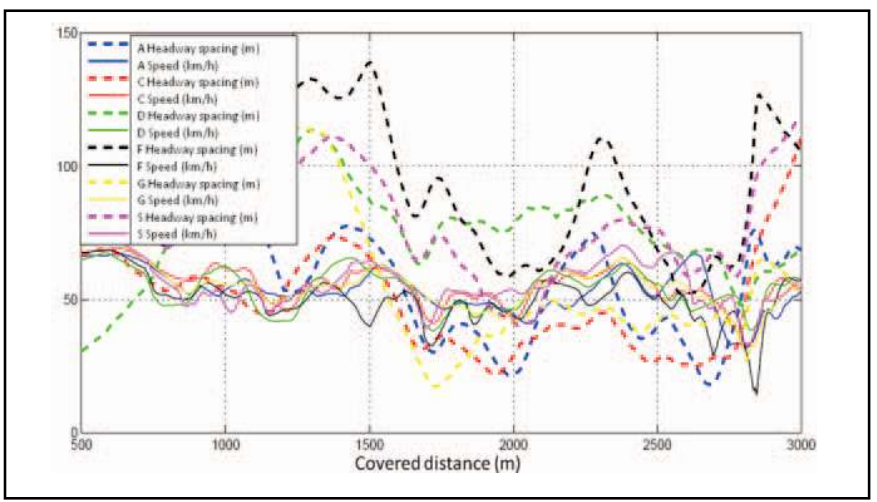

Figure 9. Speed and headway spacing for several drivers under traffic conditions.

These gains begin to be significative for several drivers. Besides, without the HMI, all the drivers had made some efforts to eco-drive by applying the rules. So when we compare both experiences (with and without HMI), the gains are supposed a few larger than the ones given in the Table 4.

TABLE IV. TEStS WITH THE PRECEEDING VeHICLE (IN TRAFFIC CONDITIONS).

\begin{tabular}{|c|c|c|c|c|}
\hline Driver & $\begin{array}{c}\text { Trip } \\
\text { Time (s) }\end{array}$ & $\begin{array}{c}\text { Covered } \\
\text { Distance } \\
(\mathbf{m})\end{array}$ & $\begin{array}{c}\text { Cumulated } \\
\text { Consumptio } \\
\mathbf{n}(\mathbf{m l})\end{array}$ & $\begin{array}{c}\text { Middle } \\
\text { Consumptio } \\
\mathbf{n}(\mathbf{I} / \mathbf{1 0 0 k m})\end{array}$ \\
\hline $\begin{array}{c}\text { C without } \\
\text { HMI }\end{array}$ & 678.92 & 10693.7 & 0.6410 & 5.9946 \\
\hline $\begin{array}{c}\text { C with } \\
\text { HMI }\end{array}$ & $\begin{array}{c}715.60 \\
(+5.4 \%)\end{array}$ & 10669.0 & $\begin{array}{c}0.6307 \\
(-1.6 \%)\end{array}$ & $\begin{array}{c}5.9117 \\
(-1.36 \%)\end{array}$ \\
\hline
\end{tabular}




\begin{tabular}{|c|c|c|c|c|}
\hline Driver & $\begin{array}{c}\text { Trip } \\
\text { Time (s) }\end{array}$ & $\begin{array}{c}\text { Covered } \\
\text { Distance } \\
(\mathbf{m})\end{array}$ & $\begin{array}{c}\text { Cumulated } \\
\text { Consumptio } \\
\mathbf{n}(\mathbf{m l})\end{array}$ & $\begin{array}{c}\text { Middle } \\
\text { Consumptio } \\
\mathbf{n}(\mathbf{l} / \mathbf{1 0 0 k m})\end{array}$ \\
\hline $\begin{array}{c}\text { D without } \\
\text { HMI }\end{array}$ & 683.13 & 10708.5 & 0.7314 & 6.8297 \\
\hline $\begin{array}{c}\text { D with } \\
\text { HMI }\end{array}$ & $\begin{array}{c}707.04 \\
(+3.5 \%)\end{array}$ & 10710.6 & $\begin{array}{c}0.7007 \\
(-4.19 \%)\end{array}$ & $\begin{array}{c}6.5423 \\
(-4.2 \%)\end{array}$ \\
\hline $\begin{array}{c}\text { S without } \\
\text { HMI }\end{array}$ & 662.24 & 10666.8 & 0.7910 & 7.4152 \\
\hline $\begin{array}{c}\text { S with } \\
\text { HMI }\end{array}$ & $\begin{array}{c}686.78 \\
(+3.7 \%)\end{array}$ & 10675.3 & $\begin{array}{c}0.6914 \\
(-12.6 \%)\end{array}$ & $\begin{array}{c}6.4760 \\
(-9.1 \%)\end{array}$ \\
\hline $\begin{array}{c}\text { F without } \\
\text { HMI }\end{array}$ & 712.97 & 10688.8 & 0.7672 & 7.1770 \\
\hline $\begin{array}{c}\text { F with } \\
\text { HMI }\end{array}$ & $\begin{array}{c}768.33 \\
(+7.7 \%)\end{array}$ & 10689.0 & $\begin{array}{c}0.6706 \\
(-12.59 \%)\end{array}$ & $\begin{array}{c}6.2734 \\
(-12.59 \%)\end{array}$ \\
\hline $\begin{array}{c}\text { G without } \\
\text { HMI }\end{array}$ & 642.43 & 10679.2 & 0.6674 & 6.2490 \\
\hline $\begin{array}{c}\text { G with } \\
\text { HMI }\end{array}$ & $\begin{array}{c}730.81 \\
(+13.76)\end{array}$ & 10700.0 & $\begin{array}{c}0.6186 \\
(-7.3 \%)\end{array}$ & $\begin{array}{c}5.7809 \\
(-7.35)\end{array}$ \\
\hline $\begin{array}{c}\text { A without } \\
\text { HMI }\end{array}$ & 684.78 & 10693.4 & 0.6459 & 6.0404 \\
\hline A with \\
HMI & $\begin{array}{c}781.58 \\
(+14.13 \\
\%)\end{array}$ & 10709.4 & $\begin{array}{c}0.6182 \\
(-4.2 \%)\end{array}$ & $\begin{array}{c}5.77287 \\
(-4.6 \%)\end{array}$ \\
\hline
\end{tabular}

The fuel consumption average of all the drivers without the HMI is $6.61 \mathrm{l} / 100 \mathrm{~km}$. With the HMI, it is $6.12 \mathrm{l} / 100 \mathrm{~km}$. The obtained fuel economy is then $7.55 \%$, what is the more, in real traffic conditions. In real traffic conditions, it can be noted that, in a safety point of view, the gains are quite high with the use of the ADAS.

TABLE V. LEGAL SPEED OVERSHOOTS IN TRAFFIC REAL CONDITIONS.

\begin{tabular}{|c|c|c|c|}
\hline \multirow{2}{*}{ Driver } & \multicolumn{3}{|c|}{ Legal Speed Overshoots (\%) } \\
\cline { 2 - 4 } & Without HMI & With HMI & Gain (\%) \\
\hline B & 18.3 & 3.38 & -79.23 \\
\hline C & 13.71 & 9.24 & $-32.6 \%$ \\
\hline D & 5.67 & 4.17 & $-26.4 \%$ \\
\hline S & 9.34 & 9.3 & $-0.42 \%$ \\
\hline F & 6.33 & 2.35 & $-62.8 \%$ \\
\hline G & 18.87 & 5.02 & $-73.39 \%$ \\
\hline A & 9.35 & 3.76 & $-59.78 \%$ \\
\hline
\end{tabular}

Table 5 shows the percentage of legal speed overshoots for all the drivers with and without HMI and computes the resulted gain between both situations. One can note the high gains and the diversity among the drivers.

\section{CONCLUSION}

An Ecological Driving Assistance System is presented in its experimental phase. From the vehicle and fuel consumption modeling, consumption optimization, a HMI module is developed in order to test this EDAS and evaluate the gains obtained in terms of economy, ecology and safety. After several experimental tests with 8 different drivers, the results permit to affirm that the conception of EDAS is promising, by obtaining around 9 to $12 \%$ fuel gain while improving the safety aspects.

\section{ACKNOWLEDGMENT}

This work is supported by the ANR (French National Research Agency) VTT program, and developed in the ANR VTT ABV (Low Speed Automation) research project (20092013). The validation of this system is going to be validated within the EU FP7 ecoDriver project.

\section{REFERENCES}

[1] IEA (International Energy Agency), "How the energy sector can delive on a climate agreement in Copenhagen", Special early except of the Work Energy Outlook 2009 for the UNFCCC meeting, Oct. 2009, Bangkok, Thaïland.

[2] IEA (International Energy Agency), " $\mathrm{CO}_{2}$ emissions from fuel combustion 2010 - highlights, Edition 2010

[3] M. Van Der Voort, M. Dougherty, M. Van Maarseveen, , "A prototype fuel-efficiency support tool”, Transportation Research Part C: Emerging Technologies, 9, 279-296, 2001.

[4] J. Barbé, G.A. Boy, M. Sans, "Gerico : A human centered eco-driving system", In Proc. Int. Conf. 10th IFAC/IFIP/IFORS/IEA Symposium on Analysis, Design, and Evaluation of Human-Machine Systems, Seoul, Korea, 2007.

[5] E. Hellstrom, A. Froberg, L. Nielsen, "A real-time fuel optimal cruise controller for heavy trucks using road topography information", SAE World Congress, number 2006-01-000, 2005, Detroit, USA.

[6] L. Nouveliere, M. Braci, L. Menhour, H-T. Luu, "Fuel consumption optimization for a city bus", UKACC Control Conference, 2008, Manchester, UK.

[7] L. Nouveliere, M. Braci, L. Menhour, H. T. Luu, S. Mammar, "Infrastructure based fuel consumption optimization of a vehicle", 9th international symposium on Advanced VEhicle Control AVEC08, 2008, Kobé, Japan.

[8] H-T.Luu, L. Nouvelière, V. Hoarau, S. Mammar, "Vehicle Speed Control For A Safety-Economical-Ecological Compromise : Development Of A Driver Assistance System", Proceedings of the AVEC10 Conference, August 2010, Loughborough, UK.

[9] H-T Luu, L. Nouvelière, S. Mammar, "Towards a Safer Ecologica Driver Aassistance System", Proceedings of the ITS World Congress, Oct. 2010, Busan,Korea.

[10] H-T Luu, L. Nouvelière, S. Mammar, "Dynamic programming for fuel consumption optimization on light vehicle", Proceedings of the IFACAAC Conference, July 2010, Munich, Germany.

[11] H-T.Luu, L. Nouvelière, S. Mammar, "Modélisation de la consommation en carburant d'un véhicule léger à partir de données expérimentales", JD-JN-MACS, March 2009, Angers, France.

[12] S. Guillaume, B. Charnomordic, J-L.Lablée, "Fispro : An open source portable software for fuzzy inference systems", www.inria.fr, 2002. 